2018;9(4):171-172. doi:10.4103/jmh.JMH 15718

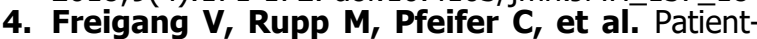
reported outcome after patient-specific unicondylar knee arthroplasty for unicompartmental knee osteoarthritis. BMC Musculoskelet Disord. 2020;21(1):1-9. doi:10.1186/s12891-020-03776-3

5. Pearle AD, van der List JP, Lee $L$, Coon TM, Borus TA, Roche MW. Survivorship and patient satisfaction of robotic-assisted medial unicompartmental knee arthroplasty at a minimum two-year follow-up. The Knee. 2017;24(2):419428. doi:10.1016/j.knee.2016.12.001

6. Hart D.J., Spector T. D. (2012). Change in body mass index during middle age affects risk of total knee arthoplasty due to osteoarthritis: A 19-year prospective study of 1003 women. The Knee; 19, 316-319.

7. Krych AJ, Reardon P, Sousa P, Pareek A,
Stuart M, Pagnano M. Unicompartmental Knee Arthroplasty Provides Higher Activity and Durability Than Valgus-Producing Proximal Tibial Osteotomy at 5 to 7 Years. J Bone Joint Surg Am. 2017;99(2):113-122. doi:10.2106/JBJS.15.01031

8. Comparison of High Tibial Osteotomy and Unicompartmental Knee Arthroplasty at a Minimum Follow-Up of 3 Years - ScienceDirect. Accessed September 22, 2021. https:// www.sciencedirect.com/ science/ article/abs/pii/S0883540312003622

9. Hasan Raza Mohammad, Stephen Mellon, Andrew Judge, Christopher Dodd David Murray (2021). The efect of age on the outcomes of cementless mobile bearing unicompartmental knee replacements. Knee Surgery, Sports Traumatology, Arthroscopy https://doi.org/ 10.1007/s00167-020-06428-0

\title{
THỰC TRANG VÀ MỨC Độ THAM GIA DİCH VUU CHĂM SÓC SỨC KHỎE TẠI NHÀ Có KẾT NỐI Y TẾ TỪ XA CỦA NGƯờI DẨN THÀNH PHỐ ĐÀ NẪNG
}

\section{TÓM TẮT}

Múc tiêu: Mô tả thực trang sử dụng dịch vụ chăm sóc sức khỏe tại nhà và tìm hiểu mức độ tham gia một số dịch vư y tế có kết nối y tế từ xa của người dấn thành phố Đà Nẵng. Phương pháp nghiên cứu: Nghiên cứu mô tả cắt ngang, được thực hiện trong tháng 03 năm 2021 trên 201 người dần đang sinh sống tại thành phố Đà Nẵng. Kết quả: Có $18,4 \%$ người đã từng sử dụng dịch vụ chăm sóc sức khỏe tại nhà. Trong số 15 dịch vụ sức khoẻ được hỏi thì mức độ rất muốn tham gia của người dân dao động từ $5,5 \%$ đến $41,3 \%$ và số người dân muốn tham gia là từ $56,7 \%$ đến $82,6 \%$. Về mức độ săn sàng tham gia của gia đình, có từ $17,9 \%$ đến $65,7 \%$ hộ gia đình sẽ tham gia các dịch vụ này khi có nhu cầu. Kết luận: Đa số người dân chưa từng sử dụng dịch vụ chăm sóc sức khoẻ tại nhà và phần đông người dân và hộ gia đình của họ sẵn sàng tham gia các dịch vụ này trong thời gian tới.

Tư khoá: chăm sóc sức khoẻ tại nhà, y tế từ xa, mức độ sẵn sàng.

\section{SUMMARY \\ THE SITUATION AND WILLINGNESS TO \\ PARTICIPATE IN HOME-CARE SERVICES WITH TELEMEDICINE OF THE RESIDENTS IN DA NANG CITY}

\footnotetext{
${ }^{1}$ Trường Đai họ Kỹ thuật $Y$ - Dược Đà Nã̃ng

${ }^{2}$ Viện Y tế công cộng và Y học dự phòng, Trường Đại học Y Hà Nôii

3Trường Đại hoc Y - Dước, Đai hoc Huê.

Chịu trách nhiệm chính: Võ Vắn Thắng

Email: vovanthang147@huemed-univ.edu.vn

Ngày nhận bài: 19.8.2021

Ngày phản biên khoa hoc: 15.10 .2021

Ngày duyệt bài: 25.10.2021
} home-care services and obtain the willingness to participate in home-care services with telemedicine of people in Da Nang city. Methods: A cross-sectional study was conducted on 201 people residing in Da Nang city in March 2021. Results: There was $18.4 \%$ of people who have ever used home-care services. Among the 15 health services questioned, the proportion of people who were tremendously willing to participate ranges from $5.5 \%$ to $41.3 \%$. The number of people who were pretty willing to participate was from $56.7 \%$ to $82.6 \%$. Regarding the level of family's willingness to participate, between $17.9 \%$ and $65.7 \%$ of households would participate in these services when needed. Conclusions: The study has shown that most people have never used home health care services and most people and their families are willing to participate in these services soon.

Keywords: home-care services, telemedicine, willingness.

\section{I. ĐẶT VẤN ĐỀ}

Đại dịch COVID-19 như là một chất xúc tác để chuyển đổi số và y tế từ xa (telemedicine) được chứng minh là một giải pháp thích hợp cho việc giảm thiểu nguy cơ lây truyền COVID-19 bắng cách ngăn chặn bất kỳ hình thức tiếp xúc vật lý trực tiếp nào, cung cấp dịch vụ chăm sóc liển tục cho cộng đồng và cuối cùng là giảm tỷ lệ mắc bệnh và tử vong khi bùng phát dịch [1]. Qua đó, người dân cộng đồng và người cung cấp dịch vụ cảm thây được hỗ trợ thuận lợi cho việc phát hiện, chẩn đoán và phòng ngừa sớm, đồng thời nó cũng giúp giảm tải áp lực cho các bênh viện.

Trước đây, các mô hình chăm CSSK chỉ có thể triển khai ngay tại bệnh viện thì giờ đây đã có thể được kết nối ngay tại nhà. Tuy nhiên, Việt 
Nam vẫn chưa có một mô hình thống nhất nào và phần lớn người dẩn chưa có hiểu biết về các dịch vụ CSSK tại nhà này. Bên cạnh đó, ngày nay thì nhu cầu chăm sóc sức khỏe tại nhà cũng là một nhu câu rất phổ biến ở người cao tuổi [2]. Một nghiên cứu ở Hà Nội năm 2021 chỉ ra rằng đa số người dân sẵn sàng tham gia và chi trả cho các dịch vụ CSSK tai nhà, ngay cả khi ho có bảo hiểm y tế và giá dịch vụ y tế từ xa là khá cao [3]. Do đó, chúng tôi tiển hành nghiên cứu này nhằm cung cấp thêm các bằng chứng về thực trang và mức độ sẵn sàng tham gia của người dân để kịp thời đẩy nhanh việc áp dụng y học từ xa hiệu quả hơn.

\section{II. ĐỐI TƯƠ'NG VÀ PHƯƠNG PHÁP NGHIÊN CỨU}

2.1 Đối tượng nghiên cứu. Người dân đang sinh sống tại thành phố Đà Nẵng.

Tiêu chuẩn lựa chơn: Người dân từ 18 tuổi trở lên, đang sinh sống và có hộ khẩu thường trú tai thành phố Đà Nẵng.

Tiêu chuẩn loại trừ: Những người không đồng ý tham gia nghiên cứu và không có mặt tại thời điểm nghiên cứu.

\subsection{Phương pháp nghiên cứu}

Thiết kế nghiên cứu: Nghiên cứu mô tả cắt ngang.

Thời gian nghiên cứu: Tháng 3 năm 2021.

Chọn mẫu và cõ̃ mẫu: Sử dụng phương pháp chọn mẫu thuận tiện, chúng tôi đã tiếp cận được 240 hộ gia đình tại thành phố Đà Nẳng, trong đó có 201 hộ đồng ý tham gia và trả lời đầy đủ các câu hỏi nghiên cứu.

Công cư thu thâp số liệu: Bô câu hỏi gồm 3 phần là thông tin chung, thực trạng và mức độ sẵn sàng tham gia dịch vụ CSSK tại nhà có kết nối y tế từ xa.

Phương pháp thu thập số liệu: Điều tra viên được tập huấn kỹ về bộ câu hỏi. Thông tin được thu thập bằng phương pháp khảo sát trực tiếp đối tượng nghiên cứu.

2.3. Xử lý số liệu. Số liệu thu thập được nhập bằng phần mềm Epidata 3.1 , làm sạch và xử lý bằng phần mềm thống kê SPSS 20.0 để phân tích theo các mục tiêu của nghiên cứu.

2.4. Đạo đức nghiên cứu. Các đối tượng tham gia được giải thích rõ mục đích, nội dung của nghiên cứu. Các thông tin thu thập được giữ bí mật và chỉ được sử dụng phục vụ cho mục đích nghiên cứu và lập kế hoạch CSSKK cho các hộ gia đình.

\section{KẾT QUẢ NGHIÊN CỨU}

3.1. Thực trạng sử dụng dịch vụ chăm sóc sức khỏe tại nhà có kết nối y tế từ xa

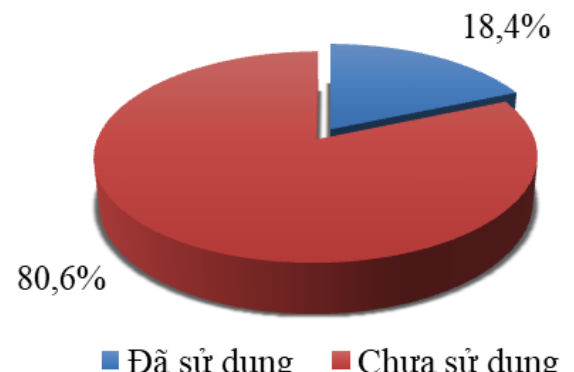

Biểu đồ 3.1. Tỷ lệ sử dụng dịch vụ chăm sóc sức khỏe tại nhà có kêt nối y tế từ xa $(n=201)$

Có $18,4 \%$ đã từng sử dụng dịch vụ chăm sóc sức khỏe tại nhà có kết nối y tế từ xa.

Bảng 3.1. Các dịch vụ chăm sóc sức khỏe tại nhà có kêt nôi y tế từ xa đã sử dụng $(n=201)$

\begin{tabular}{|c|c|c|}
\hline Dịch vụ & Số lượng (n) & Tỷ lệ (\%) \\
\hline Gọi điện hỏi bác sĩ về bệnh tật; & 109 & 54,2 \\
\hline Gửi kết quả khám, xét nghiệm, đến cán bộ y tế để được tư vấn; & 61 & 30,3 \\
\hline Khám, tư vấn từ xa bởi các cán bộ y tế qua các màn hình tương tác & 18 & 9,0 \\
\hline $\begin{array}{l}\text { Kết nối với cán bộ y tế qua các ứng dụng cài đăt trên điện thoại đế } \\
\text { hỏi bệnh hoặc xin được khám, tư vấn; }\end{array}$ & 23 & 11,4 \\
\hline Sử dụng các thiết bị theo dõi sức khoẻ từ xa & 36 & 17,9 \\
\hline $\begin{array}{l}\text { Kết nối từ xa với các thây thuốc khác thông qua các cán bộ y tế } \\
\text { đến khám, chữa bệnh tại nhà }\end{array}$ & 6 & 3,0 \\
\hline Các dịch vụ khác & 47 & 23,4 \\
\hline
\end{tabular}

Tỷ lê từng sử dụng các dịch vụ gọi điên hỏi bác sĩ về thông tin bênh tât chiếm tỷ lệ cao nhất với $54,2 \%$; và kết nối từ xa với các thầy thuổc khác thông qua các cán bộ y tế đến khám, chữa bệnh tại nhà là thấp nhất với tỷ lệ 3,0\%.

3.2. Mức độ tham gia một số dịch vụ chăm sóc sức khỏe tại nhà có kết nối y tế từ xa Mức độ sẵn sàng tham gia của người dân đối với các dịch vụ này:

1. Không tham gia 2. Tham gia; 3. Rất muốn tham gia

Mức độ sẵn sàng tham gia của gia đình đối với các dịch vụ này khi có nhu cầu: 
$\begin{array}{lll}\text { 1. Không tham gia 2. Phân vân/chưa quyết định } \quad \text { 3. Có tham gia } & \text { 2 }\end{array}$

Bảng 3.2. Mức độ tham gia của người dân và của gia đình đối với các loại hình dịch vụ tổ chức và kêt nối

\begin{tabular}{|c|c|c|c|c|c|c|}
\hline \multirow{2}{*}{ Tên dịch vụ } & \multicolumn{3}{|c|}{$\begin{array}{c}\text { Mức độ tham gia } \\
\text { của người dân }\end{array}$} & \multicolumn{3}{|c|}{$\begin{array}{l}\text { Mức độ tham gia } \\
\text { của gia đình }\end{array}$} \\
\hline & \begin{tabular}{|c|}
1 \\
$\operatorname{n(\% )}$
\end{tabular} & \begin{tabular}{|c|}
2 \\
n $(\%)$
\end{tabular} & \begin{tabular}{|c|}
3 \\
$n(\%)$
\end{tabular} & $\frac{1}{n(\%)}$ & n (\%) & \begin{tabular}{|c|}
3 \\
n (\%)
\end{tabular} \\
\hline $\begin{array}{l}\text { Tổ chức khám sức khỏe định kỳ cho các hộ gia } \\
\text { đình có nhu câu; }\end{array}$ & $\begin{array}{c}4 \\
(2,0)\end{array}$ & $\begin{array}{c}114 \\
(56,7)\end{array}$ & 83 & $\begin{array}{c}4 \\
(2,0)\end{array}$ & $\begin{array}{c}65 \\
(32,3)\end{array}$ & $\begin{array}{c}132 \\
(65,7)\end{array}$ \\
\hline $\begin{array}{l}\text { Lập hồ sơ, kế hoạch chăm sóc sức khỏe (CSSK) } \\
\text { cho từng thành viên trong gia đình; tổ chức ký } \\
\text { hơơ đồng với các hộ gia đình có nhu cầu và triển } \\
\text { khai CSSK cho từng thành viên trong gia đình } \\
\text { theo hợp đồng đã ký; }\end{array}$ & $\begin{array}{c}10 \\
(5,0)\end{array}$ & $\begin{array}{c}141 \\
(70,1)\end{array}$ & $\begin{array}{c}50 \\
(24,9)\end{array}$ & $\begin{array}{c}8 \\
(4,0)\end{array}$ & $\begin{array}{c}87 \\
(43,3)\end{array}$ & $\begin{array}{c}106 \\
(52,7)\end{array}$ \\
\hline $\begin{array}{c}\text { Cử bác sĩ đến nhà trong các trường hợp cấp cứu } \\
\text { hoặc người bệnh có nhu câuu khám chữa bệnh } \\
\text { tại nhà; }\end{array}$ & $\begin{array}{c}17 \\
(8,5)\end{array}$ & $\begin{array}{c}129 \\
(64,2)\end{array}$ & $\begin{array}{c}55 \\
(27,4)\end{array}$ & $13(6,5)$ & $\begin{array}{c}78 \\
(38,8)\end{array}$ & $\begin{array}{c}110 \\
(54,7)\end{array}$ \\
\hline $\begin{array}{l}\text { Cử người chăm sóc chuyên nghiệp đến các bệnh } \\
\text { viện chăm sóc người bệnh thay cho người nhà; }\end{array}$ & $\begin{array}{c}20 \\
(10,0)\end{array}$ & $\begin{array}{c}142 \\
(70,6)\end{array}$ & $\begin{array}{c}39 \\
(19,4)\end{array}$ & $11(5,5)$ & $\begin{array}{c}106 \\
(52,7)\end{array}$ & $\begin{array}{c}84 \\
(41,8)\end{array}$ \\
\hline $\begin{array}{l}\text { Giới thiệu người bệnh đến các bệnh viện thích } \\
\text { hợp ở nước ngoài với sự hô̂ trợ của phiên dịch } \\
\text { và cán bộ y tế đi kèm; }\end{array}$ & $\begin{array}{c}37 \\
(18,4)\end{array}$ & $\begin{array}{c}144 \\
(71,6)\end{array}$ & $\begin{array}{c}20 \\
(10,0)\end{array}$ & $18(9,0)$ & $\begin{array}{c}131 \\
(65,2)\end{array}$ & $\begin{array}{c}52 \\
(25,9)\end{array}$ \\
\hline $\begin{array}{l}\text { Giới thieêu đến các khu nghỉ dưỡng, dưỡng lão, } \\
\text { trung tâm phục hồi, chức năng thích hợp trong } \\
\text { và ngoài nước khi có nhu cầu. }\end{array}$ & $\begin{array}{c}35 \\
(17,4)\end{array}$ & $\begin{array}{c}155 \\
(77,1)\end{array}$ & $11(5,5)$ & $\begin{array}{c}20 \\
(10,0)\end{array}$ & $\begin{array}{c}145 \\
(72,1)\end{array}$ & $\begin{array}{c}36 \\
(17,9)\end{array}$ \\
\hline
\end{tabular}

Mức độ sẵn sàng tham gia và rất muốn tham gia của người dân đối với các loại hình dịch vụ tổ chức và kết nối chiếm tỷ lệ từ $81,6 \%$ đến $98,0 \%$. Mức độ tham gia của gia đình đối với các loại hình dịch vụ tổ chức và kết nối chiếm tỷ lệ từ 17,9\% đến $65,7 \%$.

Bảng 3.4. Mức độ tham gia của người dân và của gia đình đôi với các dịch vụ đăng ký và kỹ thuật có kêt nôî y tế từ xa

\begin{tabular}{|c|c|c|c|c|c|c|}
\hline \multirow{3}{*}{ Tên dịch vụ } & \multicolumn{3}{|c|}{$\begin{array}{l}\text { Mức độ tham gia của } \\
\text { người dân }\end{array}$} & \multicolumn{3}{|c|}{$\begin{array}{l}\text { Mức độ tham gia của gia } \\
\text { đình Ông/Bà }\end{array}$} \\
\hline & 1 & 2 & 3 & \begin{tabular}{|l|l|}
1 \\
\end{tabular} & 2 & \begin{tabular}{|l|l|} 
& 3 \\
\end{tabular} \\
\hline & n (\%) & n (\%) & n (\%) & n (\%) & n (\%) & n (\%) \\
\hline $\begin{array}{l}\text { Cung cấp số điền thoại liên hệ, các ứng dụng } \\
\text { để có thể kết nối hệ thống CSSK khi cần; }\end{array}$ & $\begin{array}{c}9 \\
(4,5)\end{array}$ & $\begin{array}{c}142 \\
(70,6)\end{array}$ & $\begin{array}{c}50 \\
(24,9)\end{array}$ & $\begin{array}{c}7 \\
(3,5)\end{array}$ & $\begin{array}{c}85 \\
(42,3)\end{array}$ & $\begin{array}{c}109 \\
(54,2)\end{array}$ \\
\hline $\begin{array}{c}\text { Kết nối với các bác sĩ của các phòng khám, } \\
\text { bệnh viện tuyến trên thông qua hệ thống } \\
\text { telemedicine để cùng thăm khám, hội chẩn, } \\
\text { điều trị cho người bệnh tại nhà̀; }\end{array}$ & $14(7,0)$ & $\begin{array}{c}140 \\
(69,7)\end{array}$ & $\begin{array}{c}47 \\
(23,4)\end{array}$ & $\begin{array}{c}9 \\
(4,5)\end{array}$ & $\begin{array}{c}97 \\
(48,3)\end{array}$ & $\begin{array}{c}95 \\
(47,3)\end{array}$ \\
\hline 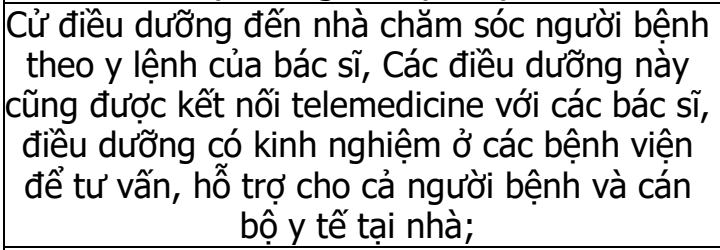 & $\begin{array}{c}25 \\
(12,4)\end{array}$ & $\begin{array}{c}130 \\
(64,7)\end{array}$ & $\begin{array}{c}46 \\
(22,9)\end{array}$ & $\begin{array}{c}13 \\
(6,5)\end{array}$ & $\begin{array}{c}89 \\
(44,3)\end{array}$ & $\begin{array}{c}99 \\
(49,3)\end{array}$ \\
\hline $\begin{array}{c}\text { Cài đặt các thiết bị theo dõi sức khoẻ từ xa } \\
\text { cho những người bệnh cần theo dõi; }\end{array}$ & $14(7,0)$ & $\begin{array}{c}147 \\
(73,1) \\
\end{array}$ & $\begin{array}{c}40 \\
(19,9)\end{array}$ & $\begin{array}{c}5 \\
(2,5) \\
\end{array}$ & $\begin{array}{c}106 \\
(52,7)\end{array}$ & $90(44,8)$ \\
\hline $\begin{array}{l}\text { Kết nối người bệnh với các giáo sư, bác sĩ giỏi } \\
\text { tại các bệnh viện trong và ngoài nước thông } \\
\text { qua hệ thống telemedicine để người bệnh } \\
\text { được khám, tư vấn và điều trị từ xa. }\end{array}$ & $\begin{array}{c}36 \\
(17,9)\end{array}$ & $\begin{array}{c}138 \\
(68,7)\end{array}$ & $\begin{array}{c}27 \\
(13,4)\end{array}$ & $14(7,0)$ & $\begin{array}{c}121 \\
(60,2)\end{array}$ & $66(32,8)$ \\
\hline
\end{tabular}


thuật chiếm tỷ lệ từ 82,1\% đến 95,5\%. Mức độ tham gia của gia đình với các loại hình dịch vụ tổ chức và kết nối chiếm tỷ lệ từ 32,8\% đến 54,2\%.

\section{BÀN LUÂN}

4.1. Thực trạng sử dụng dịch vụ chăm sóc sức khỏe tại nhà có kết nối y tế từ xa

Chăm sóc sức khỏe tại nhà là một việc cần thiết, giúp tăng sự hài lòng, nâng cao chất lượng cuộc sống của cộng đồng, giảm gánh nặng bệnh tật và kinh tế. Biểu đồ 3.1 cho thấy $18,4 \%$ người tham gia khảo sát đã từng sử dụng dịch vụ chăm sóc sức khỏe tại nhà. Kết quả này cao hơn so với nghiên cứu của Đinh Bảo Trâm và cộng sự trên bệnh nhân đột quy tại thành phố Huế khi chỉ ra chỉ có $5 \%$ bệnh nhân sử dụng dịch vụ chăm sóc tại nhà [4]. Sự chênh lệch này có thể do khác biệt về địa điểm và đối tượng nghiên cứu, chúng tôi khảo sát trên người dân nói chung, trong khi tác giả Đinh Bảo Trâm thực hiện nghiên cứu ở bệnh nhân đột quy. Điều này cho thãy ở Việt Nam mô hình cung cấp dịch vụ chăm sóc sức khỏe tại nhà chưa thực sự được sử dụng phổ biến, đa phần sự chăm sóc sức khỏe của bản thân và người bệnh đều từ người thân trong gia đình, chưa có sự kết nối với các chuyên gia trong lĩnh vực chăm sóc sức khỏe, những người đã được đào tạo về kiến thức và kỹ năng.

Tính tiện lợi của kết nối y tế từ xa và ứng dụng phổ biến công nghệ thông tin sẽ có nhiều lợi ích cho người bệnh như đã được báo cáo nhiều nơi trên thế giới. Một nghiên cứu tại bang California, Mỹ cho thấy sự thành công trong các dịch vụ từ xa với $80 \%-85 \%$ các cuộc tư vấn lâm sàng của thây thuốc chuyển sang telehealth kể từ tháng 3 năm 2020. Kết quả cho thây chăm sóc y tế từ xa $63 \%$ có chất lượng và $80 \%$ được đánh giá có hiệu quả kinh tế tốt. $76 \%$ các thầy thuốc cho rằng y tế từ xa làm tăng tính linh động và kiểm soát tốt hoạt động khám chữa bệnh, đặc biệt trong đại dịch COVID-19 [5].

Về các loại hình dịch vụ y tế từ xa đã từng sử dụng, bảng 3.1. cho thấy "Gọi điện hỏi bác sĩ về bệnh tật" chiếm tỷ lệ cao nhất là 54,2\%, tiếp theo là "Gửi kết quả khám, xét nghiệm, đến cán bộ y tế để được tư vấn" chiếm 30,3\%. Đây là loại hình phổ biến nhằm giúp người bệnh chủ động sắp xếp thời gian chăm sóc sức khỏe, tiết kiệm thời gian và chi phí đi lại, đăc biệt là các khu vực có khoảng cách xa bệnh viện, phòng khám. Khám chữa bệnh từ xa giúp bệnh nhân và nhân viên y tế hỗ trợ và quản lý bệnh hiệu quả hơn thông qua công nghệ, giảm áp lực thăm khám tại chố, hạn chế tiếp xúc đông người. Tuy nhiên, nhìn chung tỷ lệ tham gia các loại hình dịch vụ Telemedicine của người dân vẫn chưa cao, tỷ lệ tham gia các dịch vụ đa số vẫn dưới $50 \%$. Tại Nhật Bản, tỷ lể người dân tham gia Telemedicine trong bối cảnh đại dịch COVID-19 tăng lên từ $2 \%$ đến $4,7 \%$ trong thời gian tháng 4 đến tháng 9 năm 2020 [7]. Tỷ lệ này khá thấp so với nghiên cứu của chúng tôi, điêu này có thể giải thích rằng những nước có thu nhập cao, các ưu tiên, hiệu quả về chi phí, lo sợ và rủi ro an toàn và hệ thống luật pháp là những rào cản quan trọng ảnh hưởng tới sử dụng Telemedicine của người dân.

4.2. Mức độ tham gia một số dịch vụ chăm sóc sức khỏe tại nhà qua kết nối y tể từ xa. Mức độ sẵn sàng tham gia dịch vụ y tế từ xa được đánh giá trên người dân và gia đình của họ, trong đó tỷ lệ người dân không tham gia các loại hình dịch vụ dự kiến được triển khai thấp, dao động từ $2-18,4 \%$. Phần lớn người dân có nhu cầu sử dụng dịch vụ khám sức khỏe định kỳ và lập hồ sơ, kế hoạch chăm sóc sức khỏe cho từng thành viên trong gia đình (lần lượt là $98 \%$ và $95 \%$ ). Đây là một tỷ lệ khá cao và tín hiệu tích cực cho hoạt động triển khai Telemedicine đến người dân, nhằm phục vụ nhu cầu chăm sóc sức khỏe toàn diện, tối ưu. Tỷ lệ phân vân tham gia dịch vụ giới thiệu đến các khu nghỉ dưỡng, dưỡng lão, trung tâm phục hồi, chức năng thích hợp trong và ngoài nước khá cao (chiếm $72,1 \%)$, kết quả này là dễ hiểu khi mô hình nghì dưỡng, dưỡng lão ở nước ta chưa phát triển. Trong đó, yếu tố ảnh hưởng lớn nhất là chi phí dịch vụ, mức sống trung bình của người dân tham gia khảo sát gần 9 triệu/tháng, ở mức vừa đủ để trang trải cuộc sống hàng ngày, đây có thể là lý do dẫn đến sự phân vân lựa chọn sử dung dịch vu này. Đà Nẵng là nơi xảy ra tâm dịch COVID-19 vào tháng 7/2020, cũng có thể là lý do góp phần tỷ lệ sẵn sàng tham gia sử dụng y tế từ xa của người dân cao như vậy.

Phần lớn người tham gia đều mong muốn được kết nối với các bác sĩ, điều dưỡng để được tư vấn, hỗ trợ thăm khám, tư vấn và điều trị từ xa. Kết quả này của chúng tôi tương đồng với nghiên cứu của Đỗ Thị Thanh Toàn tại Hà Nội [7]. Đây là bằng chứng rất thuyết phục để triển khai các loại hình dịch vụ y tế từ xa đến người dân, cũng như hoat đọng kết nối telemedicine giữa các giáo sư, bác sĩ, điều dưỡng giỏi, có kinh nghiệm để cùng thăm khám, hội chẩn, điều trị cho người bênh tại nhà. Đối với dịch vụ khám chữa bệnh từ xa bằng cách cung cấp số điên thoại liên hệ, các ứng dụng để có thể kết nối hệ 
thống chăm sóc sức khỏe khi cần, người dân đồng ý tham gia và rất muốn tham gia chiếm tỷ lệ rất cao, lên đến $95,5 \%$, trong khi đó tỷ lệ hộ gia đình phân vân là $42,3 \%$. Kết quả này khá tương đồng với một nghiên cứu tại Đà Nẵng thực hiện trên bệnh nhẩn đái tháo đường khi chỉ ra có đển $52,4 \%$ người phân vân sử dụng khám chữa bệnh từ xa[8]. Một số yếu tố như tình trạng bệnh lý, đã từng nghe về Telemedicine, khả nẳng chi trả và lo ngại về tính an toàn, bảo mật của dịch vụ có thể ảnh hưởng đến việc sử dụng các dịch vụ chăm sóc sức khỏe từ xa $[3,8]$.

\section{KẾT LUẬN}

Kết quả nghiên cứu chỉ ra rằng tỷ lệ người dân sử dụng dịch vụ chăm sóc sức khỏe tại nhà có kết nối y tế từ xa chưa cao. Tuy nhiên phần lớn người dân và gia đình sẵn sàng tham gia loại hình dịch vụ chăm sóc sức khỏe này, tỷ lệ dao động giữa các dịch vụ khác nhau. Do đó, đây là bằng chứng rất quan trọng để có thể triển khai các mô hình chăm sóc sức khoẻ từ xa nhằm chăm sóc sức khỏe toàn diện cho người dân, đặc biệt trong bối cảnh đợt dịch COVID-19 lần thứ tư hiện nay ở Việt Nam đã và đang diễn ra hết sức phức tạp.

\section{TÀI LIẸU THAM KHẢO}

1. Song $X$, Liu $X$, Wang C (2020), "The role of telemedicine during the COVID-19 epidemic in China- experience from Shandong province". Critical Care; 24(1):1-4.

2. Võ Văn Thẳng, Võ Nũ̃ Hồng Đức ${ }_{\text {L }}$ Lương Thanh Bảo Yển, Vũ Thị Cúc, Nguyên Phúc
Thành Nhân (2021), "Đánh giá tình trạng và nhu cầu chăm sóc sức khoẻ của người cao tuổi tại tỉnh Thừa Thiên Huế". Tap chí Y học Việt Nam; 498(2): 35-39.

3. Nguyến Thi Lan Anh, Bùi Thi Ngoc Minh, Nguyễn Thị Thu Trang, Huỳnh Phước Tho, Nguyển Lân Hiếu, Đố Thị Thanh Toàn, Lưu Ngọc Hoạt (2021), "Nhu cầu và khả năng chi trả của người dân cho dịch vụ chăm sóc sức khoẻ tại nhà theo mô hình Buurtzorg có kết nối y tế từ xa tại quận nam Từ Liêm, Hà Nội năm 2021". Tạp chí Y hoc Viêt Nam; 501(2): 199-204.

4. Đinh Bảo Trâm và CS (2020), "Nhu cầu sử dung dịch vụ chăm sóc tại nhà của bệnh nhân sau đốt quy tai thành phố Hiuê, Việt Nam". Tap chí Y Dược học; 10 (1): 19 - 24.

5. Malouff, T. D., TerKonda, S. P., Knight, D., Perlman, A. I., Munipalli, B., Dudenkov, D. V., ... \& Buskirk, S. J. (2021). Physician Satisfaction With Telemedicine During the COVID-19 Pandemic: The Mayo Clinic Florida Experience. Mayo Clinic Proceedings: Innovations, Quality \& Outcomes, 5(4), 771-782.

6. Miyawaki, A., Tabuchi, T., Ong, M. K., \& Tsugawa, Y. (2021). Age and Social Disparities in the Use of Telemedicine During the COVID-19 Pandemic in Japan: Cross-sectional Study. Journal of medical Internet research, 23(7), e27982.

7. Đố Thị Thanh Toàn, Lưu Ngọc Minh, Đinh Thái Sơn và cộng sự' (2018), "Nhu câu tham gia dịch vụ chăm sóc sức khỏe tại nhà của người dân tại một khu đô thị Hà Nội". Tạp chí Nghiên cứu y học; 113 (4), 148-157.

8. Quách Hứu Trung, Võ Thi Hồng Hướng (2021). Kiến thức và nhu cầu về sử dụng dịch vụ khám chữa bệnh tữ xa của bệnh nhẩn đái tháo đường tại thành phố Đà Nằng. Tạp chí Nội tiết và Đái tháo đường; (46): 239-246.

\section{KẾT QUẢ ĐIỀU TRI UNG THƯ BIỂU MÔ ĐẠI TRÀNG Ở BỆNH NHÂN TRẺ TUỔI TẠI BỆNH VIỆN K GIAI ĐOẠN 2016-2020}

\section{TÓM TẮT.}

Mục tiêu:Đánh giá kết quả điều trị ung thư biểu mô đại tràng ở bệnh nhân trẻ tuổi tại bệnh viện $K$. Đối tượng và phương pháp nghiển cứu: Nghiên cứu mô tả hồi cứu kết hợp tiến cứu trên bệnh nhân từ 30 tuổi trở xuống được chẩn đoán ung thư đại tràng và điều trị tại Bệnh viện $K$ từ tháng 1/2016 đến tháng 12/2020. Kết quả: Tỷ lệ bệnh nhân đáp ứng hoàn

\footnotetext{
${ }^{1}$ Trường Đại học Y Hà Nội

${ }^{2}$ Bênh viên $K$

Chịu trách nhiệm chính: Nguyễn Thị Mai

Email: nguyenmai95hmu@gmail.com

Ngày nhận bài: 23.8.2021

Ngày phản biện khoa học: 20.10.2021

Ngày duyệt bài: 2.11.2021
}

Nguyễn Thị Mai ${ }^{1}$, Vũ Hồng Thăng ${ }^{1,2}$

toàn, tái phát sau điều trị lần lượt là 65,3\% và 20,4\%. Tỷ lệ bệnh nhân tái phát liên quan có ý nghĩa với nồng độ CंEA trước điều trị. Tỷ lệ sống thêm toàn bộ 5 năm là $37 \%$ và trung vị thời gian sống thêm toàn bộ 5 năm là $28,1 \pm 8,26$ tháng. Tỵ lệ sống thêm toàn bộ 5 năm có sự khác biệt giứa các giai đoạn bệnh, sự khác biệt có ý nghĩa thổng kê. Kết luận:Tỷ lệ sống thêm 5 năm toàn bộ là 37\%, liên quan có ý nghĩa thống kê với tình trạng di căn hạch và giai đoạn bệnh.

Tí khóa: ung thư đại tràng, bệnh nhân trẻ tuổi, kết quả điều trị.

\section{SUMMARY \\ TREATMENT OUTCOMES OF COLON CANCER IN YOUNG PATIENTS AT $K$ HOSPITAL IN PERIOD 2016-2020}

Aims: To evaluatethe treatment outcomes of 